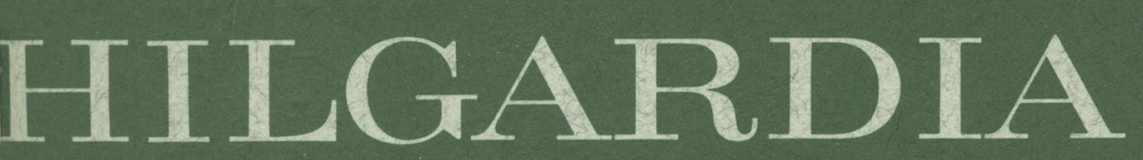

A JOURNAL OF AGRICULTURAL SCIENCE PUBLISHED BY THE CALIFORNIA AGRICULTURAL EXPERIMENT STATION

Volume 35, Number 3 September, 1963

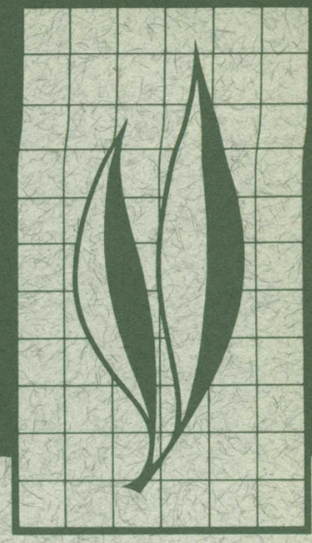

\title{
Tests of Thick Fiberglass Filters for Subsurface Drains
}

\author{
Darrell G. Watts and James N. Luthin
}




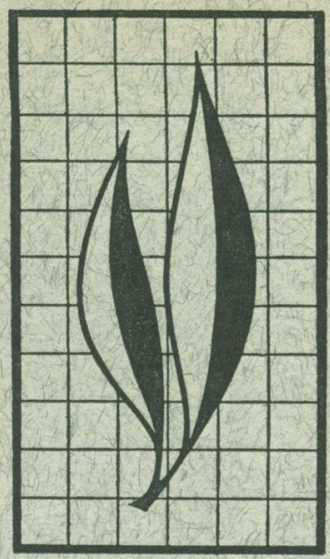

A series of tests was made to evaluate the use of thick fiberglass materials as a substitute for gravel filters around subsurface drains and to study the effect of perforation spacing on inflow to filtered drain pipe.

From the results of the experiments and studies of the background information, the following is concluded:

1. Within the range of loading ordinarily expected under field conditions, the thickness of the fiberglass filter materials tested is greatly reduced from that measured in the uncompressed state. This change in thickness depends on (a) initial thickness, (b) initial density, and (c) to some extent, manufacturing processes.

2. The hydraulic conductivity of the fiberglass materials was high and essentially varied little with load or samples of different thicknesses and densities. All " $K$ " values measured were within the range given by other workers for clean sands or mixtures of clean sands and gravels.

3. For ponded water conditions, inflow to a filtered drain is greater than that to a nonfiltered drain with a similar perforation arrangement. Inflow to the filtered drain was affected very little by perforation spacing, whereas inflow to the nonfiltered drain varied considerably. Experimental results were influenced by a time effect not related to perforation spacing.

\section{THE AUTHORS:}

Darrell G. Watts is Instructor, Agricultural Engineering Department, Oregon State University, Corvallis. James N. Luthin is Professor of Irrigation, Davis. 


\section{Tests of Thick Fiberglass Filters for Subsurface Drains ${ }^{1}$}

\section{INTRODUCTION}

When dRAINAGe systems are installed on irrigated lands, a gravel envelope or "filter" is commonly placed around the drain tube. (The term gravel is a misnomer since the material is often coarse sand.) There are three advantages to this procedure: 1. By reducing exit gradients, the gravel serves to stabilize the earth around the drain, preventing soil movement into openings in the line. 2 . The rate of water movement into a gravel-filtered drain, which acts as a porous tube, may be several hundred per cent greater than into a drain covered only with soil, which acts as a tube with discrete openings along its length. 3. Gravel also acts as a bedding material which reduces shifting and settling of the tile.

There are several possible disadvantages when gravel is used as a filter material: 1. Cost may be prohibitive in some areas because of hauling expenses. 2. Pit-run gravel may not effectively prevent soil movement into the drain under certain conditions. 3 . It may be difficult to surround the tile with gravel.

The use of very thin fiberglass sheets (0.02 inch) as a low-cost substitute for gravel has met with moderate success. Of the types tried thus far, most have satisfactorily prevented the movement of soil into drains. The thin sheets are rather fragile, however. According to Nelson (1960), they should be handblinded before backfilling to prevent tearing and breaking. Whether this material will allow an increased flow rate of water into the drain, as a gravel filter does, is still a question.

Some properties of a new filter material of thick fiberglass ( 0.5 inch or greater), similar to that used in household insulation, are reported in this paper. Since it is stronger than the thin fiberglass previously mentioned, it requires no special handling in installation. It is also cheaper than gravel in many cases. Since fiberglass is an industrial product, its filtering properties can be strictly controlled in manufacture, giving it an advantage over the highly variable pit-run gravel. Also, this material may be thick enough to permit lateral movement of water between its fibers, thus increasing the flow rate of water from soil to drain just as a gravel filter does. This would probably be true if the hydraulic conductivity of the fiberglass were at least twice that of the surrounding soil.

Thick fiberglass filters are now being used in California's Imperial Valley where some severe problems have been encountered in drain installation and operation. Some new installations are being made with 8 - or 10-foot sections of perforated pipe having rigidly connected joints. The pipe is laid with the perforations facing upwards, and a thick fiberglass mat is unrolled on top. The weight of the backfill soil on the mat causes it to bend around the sides of the pipe and conform to the shape of the drain.

The experiments described here were

\footnotetext{
${ }^{1}$ Submitted for publication November 12, 1962.
} 
TABLE 1

LIST OF FIBERGLASS MATERIALS TESTED

\begin{tabular}{|c|c|c|c|}
\hline Sample number & Initial density & Initial thickness & Average fiber diameter \\
\hline & pounds per cubic foot & inches & inches \\
\hline 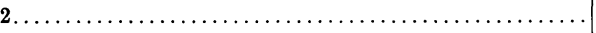 & 0.75 & 2.0 & 0.00015 \\
\hline 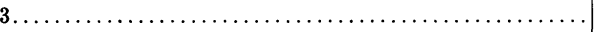 & 1.00 & 1.5 & \\
\hline 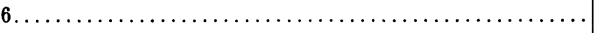 & 1.50 & 2.0 & -0.00003 \\
\hline 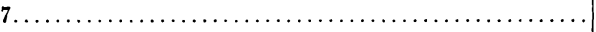 & 2.00 & 1.5 & J \\
\hline
\end{tabular}

designed to provide more information about the performance of the perforated pipe and thick fiberglass filter combination. The hydraulic conductivity of several fiberglass materials was ascertained when they were in a compressed state similar to that expected under soil load. The thickness of the materials under different pressures was determined.

Since soil conditions are quite variable, it is difficult to calculate, without detailed information on specific situations, the exact load on a filter under a given depth of earth cover. An estimate of average pressure on the filter can be obtained, however, by first calculating the load per lineal foot of drain with the appropriate Marston conduit load formula. (See, for example, Roe and Ayres, 1954.) This load is then divided by the plan view area of a footlong section of drain pipe. For example, a 6 -inch diameter drain buried under 6 feet of wet clay in a 2-foot-wide trench will have an estimated load of 683 pounds per foot. (Note that values taken from the nomographs in the reference must be divided by 1.5 to eliminate the "safety factor.") Dividing 683 by $72 \mathrm{in}^{2}$ of area yields an average load of 9.5 pounds per square inch (psi). This does not adequately describe the pressure distribution around the drain, but should serve as a guide. Calculations by this method indicate that a range of 2 to 10 psi may cover many conditions encountered in the field. Laboratory tests were made accordingly.
The effect of perforation spacing on flow into a filtered drain was examined. Present specifications for location and spacing of perforations on drain pipe do not consider the influence of a filter on inflow. In laboratory studies of perforation spacing, a measure of the effect of the filter was made by conducting the spacing-inflow experiment on both filtered and nonfiltered drains.

\section{EQUIPMENT AND PROCEDURE}

\section{Physical Tests of Fiberglass}

Samples of seven different fiberglass materials were selected for study, as shown in table 1 . The samples which had a low bulk density in the uncompressed state are similar to the fiberglass materials now being installed as drain filters. The remainder of the samples were more dense than any of the materials thus far used in the field. Observation of field operations has indicated that some of the very light insulating materials (that is, $1 / 2$ pound, $3 / 4$ inch) ${ }^{2}$ may not be strong enough to withstand the rough treatment given the filter material during installation. Consequently, the denser materials may be more satisfactory from the standpoint of strength. The selection of materials to be tested was made accordingly.

Thickness versus load measurements were made by compressing two samples of each material on a testing machine

$21 / 2$ pound and $3 / 4$ inch represent bulk density and thickness of the uncompressed mats. 
and measuring the thickness with a dialtype micrometer. The samples, which were flat disks of material 8.65 inches in diameter, were loaded from 2 to 10 psi in 2 psi increments. Thickness was read directly to the nearest 0.001 inch as shown in table 2. Loads were registered within a tolerance of $0.05 \%$.

The hydraulic conductivity values for the fiberglass materials were determined in the following manner. A 4-inch square sample of material was saturated with water, placed between two $4 \times 7 \times$ $5 / 8$-inch plastic blocks, and compressed to a specified thickness by means of "C" clamps located at each corner of the blocks. The thickness corresponded to a given load per unit area as previously determined. The sides of the blocks were sealed with plastic tape and the ends with pieces of soft rubber pressed between the blocks. The tape was pressed firmly against the sides of the fiberglass by means of two hard plastic strips clamped to either side of the blocks. Water from a constant head source was admitted to the space at one end of the sample through a supply tube at one end of the top block. The outflow from the sample was removed by a similar tube in the opposite end of the block. The differential head across the sample was measured by means of two water manometers tapped into the top block near the inlet and outlet tubes.

Before making a measurement, the open end of the outlet tube was adjusted to a height above the sample such that water would slowly drip from the tube. The time required to collect $200 \mathrm{ce}$ of water and the differential head across the sample were recorded. Measurements over an extended period of time could not be made since dissolved air in the tap water used for testing gradually came out of solution and collected at the upstream end of the sample, greatly restricting the flow. This difficulty was avoided if measurements were made soon after the flow was established.

\section{Effect of Perforation Spacing on Inflow to Drains}

Equipment: For this study a steel tank 8 feet long, 3 feet wide, and 6 feet high was constructed. Across both ends of the tank at a distance of 2 feet from the bottom, a strip of metal was removed. In each of the slots thus made, one half of a longitudinally split piece of 5-inch OD (outside diameter) thinwall steel pipe was inserted projecting inward and welded to the tank. The half-sections of pipe each represent one half of a 3-foot length of drain tube. Before installation the pipes had been drilled with rows of $1 / 4$-inch diameter holes. Hole spacing was $1 \frac{1}{2}$ inches longitudinally and in $45^{\circ}$ intervals around the circumference. At installation the pipe sections were placed so the top and bottom rows of holes were $221 / 2^{\circ}$ from a vertical line representing the diameter of the pipe. This was done to avoid the

TABLE 2

VALUES OF THICKNESS VERSUS LOAD FOR THE FIBERGLASS MATERIALS

\begin{tabular}{|c|c|c|c|c|c|}
\hline \multirow{2}{*}{ Material } & \multicolumn{5}{|c|}{ Thickness, ${ }^{*}$ in inches, for loads of: } \\
\hline & 2 psi & 4 psi & $6 \mathrm{psi}$ & $8 \mathrm{psi}$ & $10 \mathrm{psi}$ \\
\hline 0.75 -pound, 1.5 -inch. . & 0.159 & 0.117 & 0.099 & 0.088 & 0.082 \\
\hline 0.75-pound, 2.0-inch.. & 0.207 & 0.157 & 0.134 & 0.121 & 0.112 \\
\hline 1.00 -pound, 1.5 -inch... & 0.353 & 0.263 & 0.222 & 0.199 & 0.183 \\
\hline 1.00-pound, 2.0 -inch ... & 0.352 & 0.279 & 0.244 & 0.223 & 0.208 \\
\hline 1.50 -pound, 1.5 -inch.... & 0.315 & 0.247 & 0.214 & 0.194 & 0.181 \\
\hline 1.50-pound, 2.0-inch.. & 0.434 & 0.324 & 0.276 & 0.248 & 0.229 \\
\hline 2.00-pound, 1.5 -inch.. & 0.355 & 0.242 & 0.195 & 0.168 & 0.151 \\
\hline
\end{tabular}

- Average of two loading tests.

$\dagger$ Pounds per square inch. 


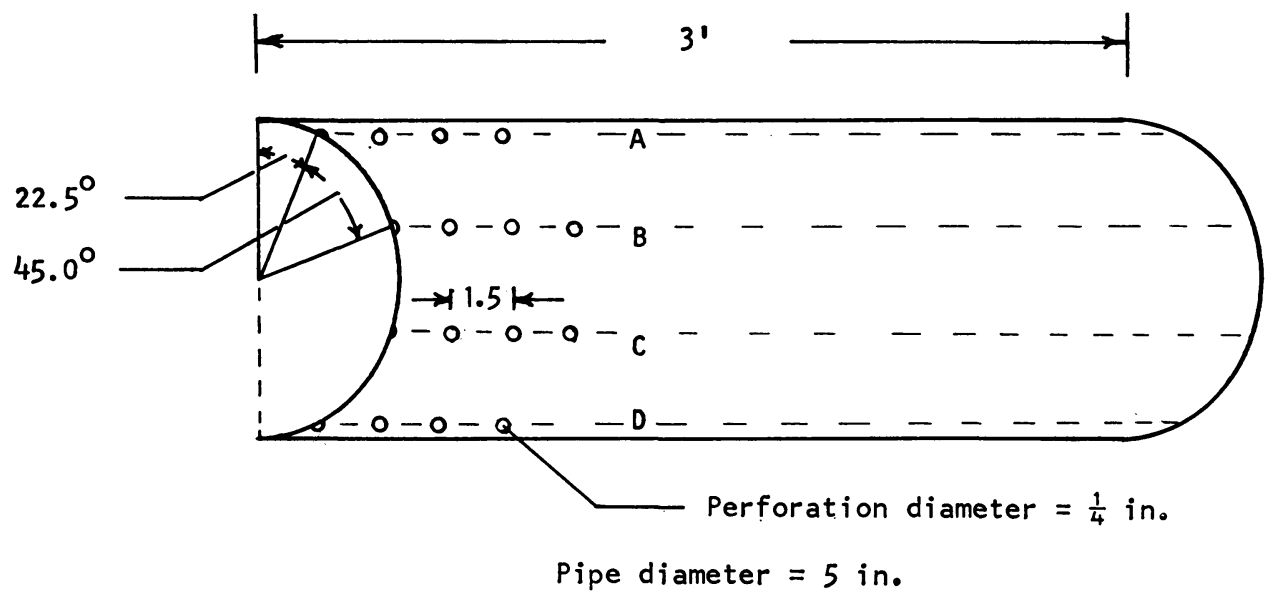

Fig. 1. Orientation of perforations in experimental drain.

problem of welding along the edge of semicircular holes without plugging them or changing their shape. Figure 1 illustrates the geometry of the hole spacing.

A collecting trough of steel plate was welded to the outside of the tank along the length of each drain. This allowed access to the drain tube so that holes could be plugged or opened. The water level in the drains could be regulated by controlling the depth of water in the collecting troughs. To complete the drain installation, one of the pipe sections was covered with a mat of 0.75 pound, 1.5-inch fiberglass material.

Before filling the tank with soil, a vacuum drainage system of 1-inch diameter ceramic tubes was laid in the bottom of the tank. The 1-foot-long tubes were connected to form a continuous section running the length of the tank. One end was closed, and the other end connected to a vacuum pump. The purpose of this system was to facilitate rapid drainage of the tank to settle the soil before beginning the experiments. An 8-foot length of 1/2-inch diameter perforated pipe was also laid in the bottom of the tank. The initial saturation of the soil in the tank was accomplished by forcing water through this pipe under very low pressure. This allowed the wetting of the soil from the bottom, which reduced the problem of entrapped air.

The soil used was Yolo clay loam. In filling the tank, the loose soil was placed to a depth of about 2 feet, saturated, and drained by the ceramic section to a water content slightly below field capacity. The tank was then filled completely with soil and the same procedure repeated. After settling, a 5-foot depth of soil was measured in the tank.

Before the experiments were begun, the perforated drains at the ends of the tank were plugged and the water table again raised from the bottom of the tank to a level 6 inches above the soil surface. This water level was maintained with a float valve connected to a pressure line at the top of the tank.

Experimental Procedure: Measurements of inflow to both the filtered and unfiltered drains at the ends of the tank were made for the following spacings of perforations. (See figure 1 for orientation of the letter-designated rows.)

Measurements of the inflow to both the filtered and nonfiltered drains at the ends of the tank were made using 1.5-, 3 -, and 6-inch spacings when perforations in only row A were open, when rows $A$ and $B$ were open, and when rows $\mathrm{A}, \mathrm{B}, \mathrm{C}$, and $\mathrm{D}$ were open. 


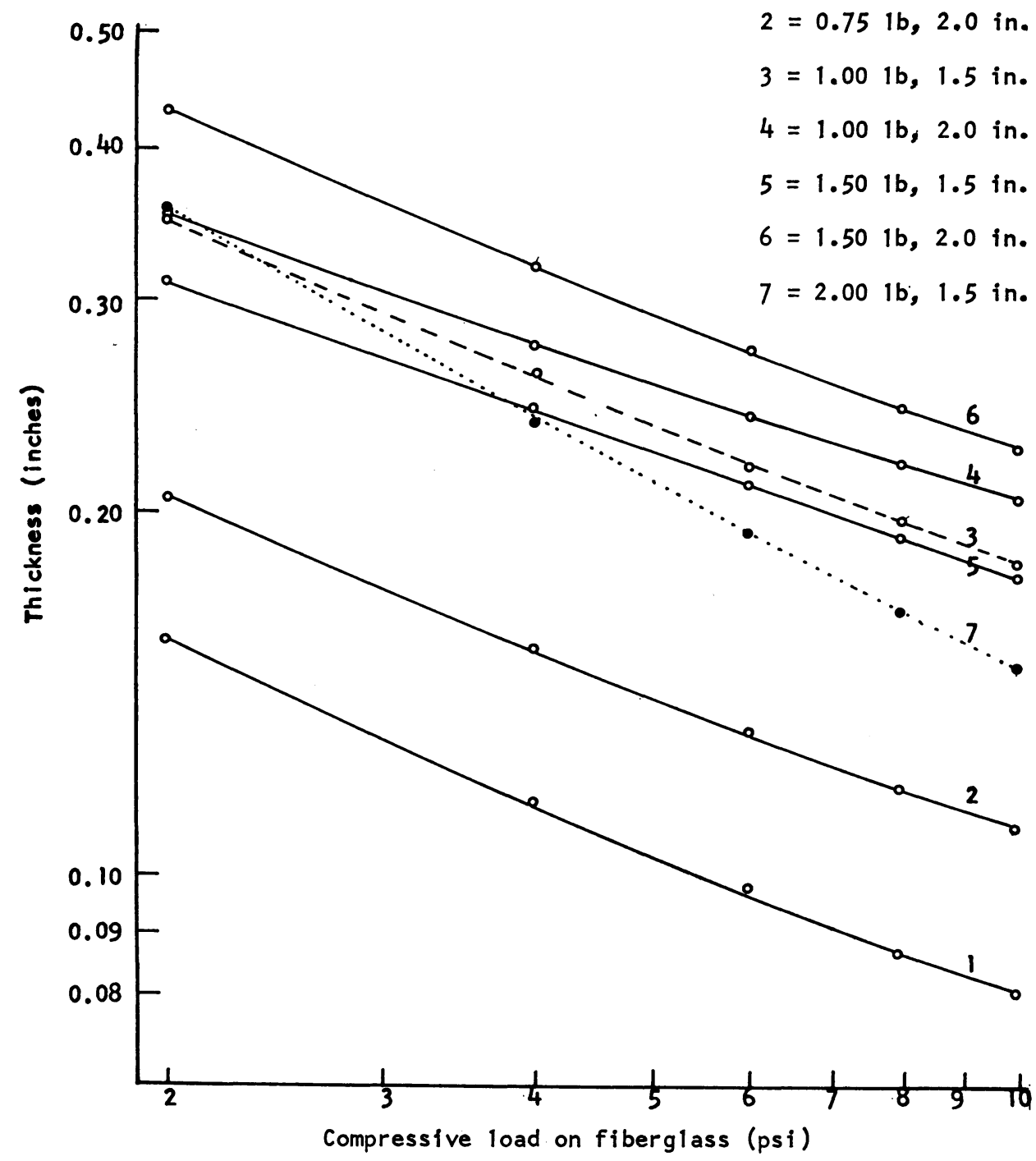

Fig. 2. Thickness versus load characteristies of fiberglass materials.

In addition, measurements were made on the filtered drain using 12- and 36inch spacings with row $\mathrm{A}$ open, and using a 12-inch spacing with rows $\mathrm{A}$ and $B$ open. After a given perforation spacing was set in a drain, a period of 20 hours was allowed to elapse before the effluent was measured for a 4-hour period.

The measurements in which all four rows of perforations were open were first made on the filtered drain. That drain was then closed and all the required measurements immediately made on the nonfiltered drain. After closing this drain again, the remaining measurements were made on the filtered drain. Since the dissolving of entrapped air and microbial action may alter conditions in a short period of time, it was 
TABLE 3

VALUES OF HYDRAULIC CONDUCTIVITY,* “ $\mathrm{K}$," VERSUS LOAD FOR THE FIBERGLASS MATERIALS

\begin{tabular}{|c|c|c|c|c|c|}
\hline \multirow{2}{*}{ Material } & \multicolumn{5}{|c|}{ “ $\mathrm{K}$," in feet/hour, for loads of: } \\
\hline & $2 \mathrm{psi}$ & $4 \mathrm{psi}$ & $6 \mathrm{psi}$ & 8 psi & $10 \mathrm{psi}$ \\
\hline $1=0.75$-pound, 1.5 -inch. . & 20.89 & 11.54 & 8.09 & 7.02 & 5.94 \\
\hline $2=0.75$-pound, 2.0 -inch $\ldots$ & 20.32 & 10.90 & 7.81 & 6.70 & 5.53 \\
\hline $3=1.00$-pound, 1.5 -inch $\ldots \ldots \ldots$ & 38.13 & 20.90 & 14.12 & 12.54 & 9.99 \\
\hline $4=1.00$-pound, 2.0 -inch $\ldots \ldots \ldots \ldots \ldots \ldots \ldots \ldots \ldots$ & 38.68 & 22.61 & 17.08 & 14.62 & 12.65 \\
\hline $5=1.50$-pound, 1.5 -inch $\ldots$ & 25.10 & 14.76 & 11.30 & 8.92 & 7.50 \\
\hline $6=1.50$-pound, 2.0 -inch $\ldots$. & 29.40 & 16.77 & 12.10 & 9.70 & 8.13 \\
\hline $7=2.00$-pound, 1.5 -inch $\ldots$ & 38.85 & 15.29 & 10.21 & 7.40 & 5.87 \\
\hline
\end{tabular}

* Water temperature $=73^{\circ} \mathrm{F}$.

felt that similar measurements would be more comparable if not separated by an extremely long time period.

During the course of the measurements, the collection troughs on the drains were covered with plastic sheeting to reduce evaporation losses.

\section{DISCUSSION OF RESULTS}

\section{Physical Tests of Fiberglass}

The results of the loading tests are plotted logarithmically in figure 2, which shows the relationship between thickness and compressive load. All fiberglass materials were compressed greatly by a small load. Other than this, it is difficult to make any generalized statements about the behavior of the materials tested. If several samples of varying densities, but with the same initial thickness, are loaded, one might expect the more dense materials to become less compressed under a given applied load. This is not necessarily true, however, as may be seen by comparing the curves for the 2-pound, 1.5-inch and the 1.5-pound, 1.5-inch materials.

In the manufacturing process the fibrous material is treated with a phenolic resin while in a very loose condition. The fibers are then compressed to the desired thickness and blasted with hot air to cure the resin. After curing, the resin acts as a bonding agent to pre- serve the desired shape and density of the fiberglass. For a given product density the resistance to compression is partly a function of the compression of the fibers before the bonding agent is cured. It is assumed that the dissimilar loading characteristics (as compared to the other samples) of the 2-pound, 1.5inch material are explained by a difference in prebonding compression.

The hydraulic conductivity of all the materials decreased as load was applied and the materials became compressed (see table 3). Figure 3, a logarithmic plot of hydraulic conductivity versus compressive load, shows this effect graphically. It is noteworthy, however, that all of the measured conductivities fall in the range of values given by other workers for clean sands or mixtures of clean sands and gravels. Todd (1960) shows values ranging from approximately $2 \times 10^{1}$ to $2 \times 10^{4} \mathrm{gal} / \mathrm{ft}^{2} /$ day $(0.11$ to $110.0 \mathrm{ft} / \mathrm{hr})$ at $60^{\circ} \mathrm{F}$. For the experiments reported here, the results, corrected to $60^{\circ} \mathrm{F}$, ranged from 4.59 to $32.10 \mathrm{ft} / \mathrm{hr}$. The range of hydraulic conductivity values expected for "gravel" filter material and those recorded for fiberglass do not vary greatly when loads of the same magnitude as those expected in the field are applied. It appears, therefore, that immediately after installation a drain filter of thick fiberglass is comparable to gravel in conductivity. 


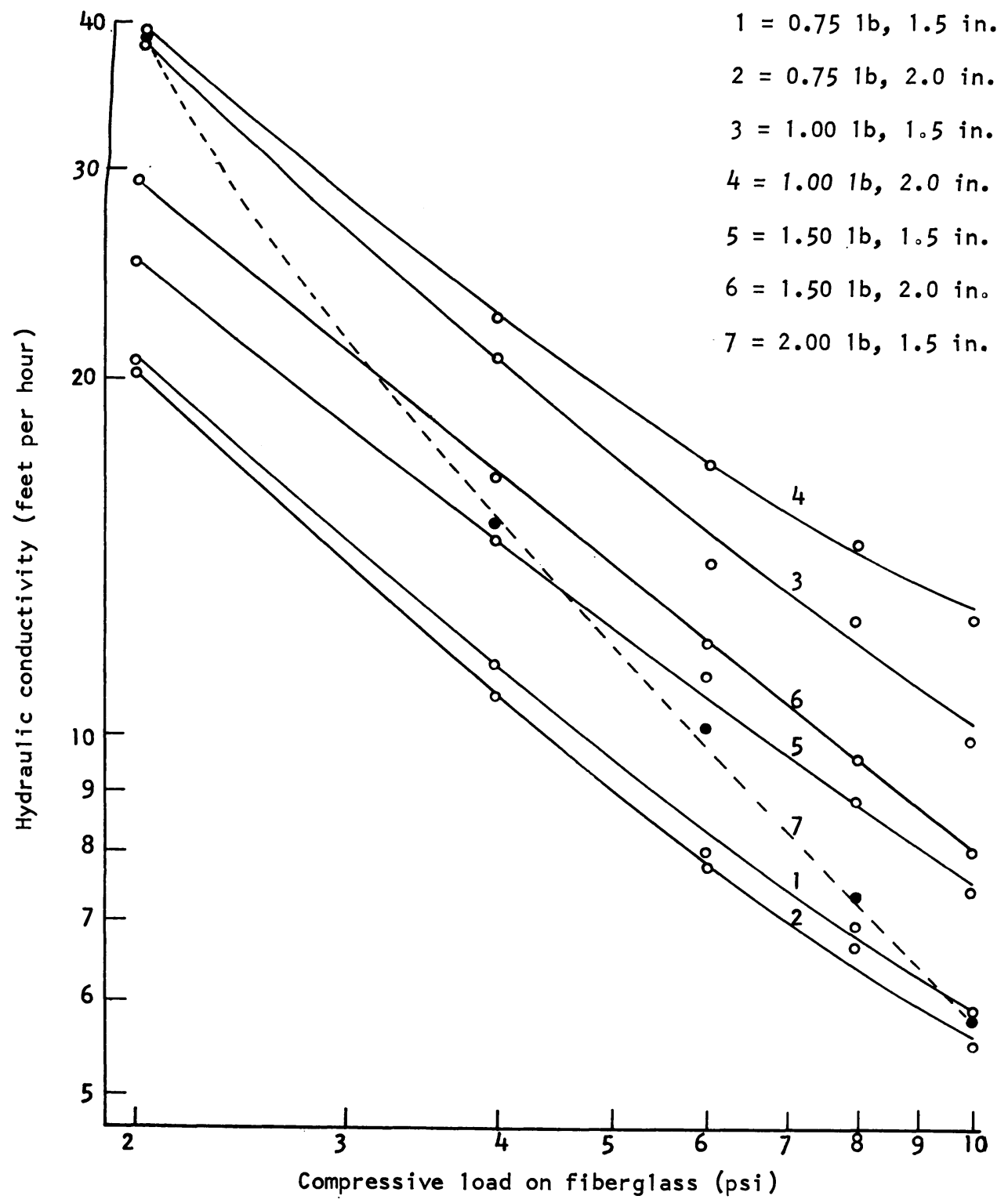

Fig. 3. Relationship of hydraulic conductivity to load.

\section{Effect of Perforation Spacing on Inflow to Drains}

A plot of $\frac{Q_{\text {filtered }}}{Q_{\text {nonfiltered }}}$ as a function of perforation spacing (figure 4; also see table 4) shows that in all but one case (where rows $\mathrm{A}$ and $\mathrm{B}$ were open) the outflow from the filtered drain was greater than that from the nonfiltered drain for a given perforation spacing. This effect is particularly striking in the case where only one row of perforations (row A) was opened in the halfdrain. For a 6 -inch perforation spacing the rate of flow from the filtered drain was over 17 times greater. This indicates that the filtered drain tends to function as a porous tube and effects an 


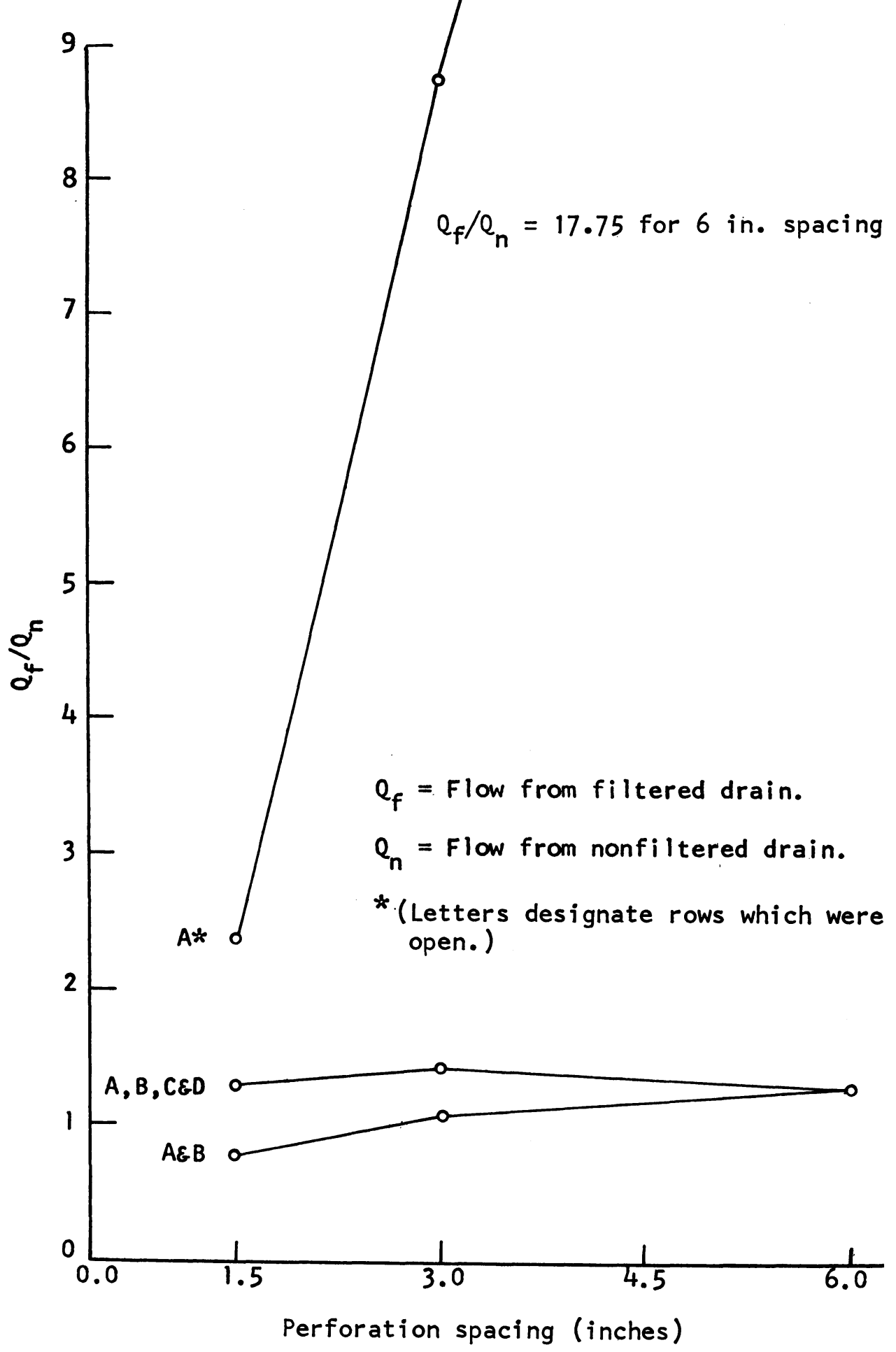

Fig. 4. Relationship between $\frac{Q_{\text {filtered }}}{Q_{\text {nonfiltered }}}$ and perforation spacing. 
increase in the quantity of water moving into the drain per unit time.

Reference to figure 5, a graph of measured outflow versus perforation spacing, shows that for the filtered drain the outflow was considerably greater when four rows of perforations were open than when either one or two rows were open. In the latter two cases outflow was more or less the same and varied little with perforation spacing. If the fiberglass filter were as permeable as a clean sand, and offered little resistance to the passage of water, it would seem that outflow should be almost constant for all three variations in the number of perforation rows. It appears that either the fiberglass was not as permeable as laboratory tests indicated or other factors not previously accounted for affected the results.

There are several possible causes of the difference in rate of outflow between the 1- and 2-row cases and the 4-row case. The 4-row experiment was first run on the filtered drain. The perforations in that drain were then closed, and the complete series of experiments run on the nonfiltered drain before the series was completed on the filtered drain. A period of 20 days elapsed between the closing and reopening of the filtered drain. It is possible that microbial ac- tion may have reduced soil permeability during this time.

After the filtered drain was reopened, air continued to bubble out of the perforations for several days. During laboratory conductivity experiments on fiberglass it was observed that air trapped at the water-fiberglass interface on the upstream side of a test sample greatly reduced the rate of water movement. It is possible that air caught at the fiberglass-soil interface could have in a similar manner restricted the entry of water into the filter. However, once water entered the filter it was able to move freely, since during the test in which 2 rows of perforations were opened, water was observed to move down through the filter past the top row of perforations and out through the bottom openings, indicating that the fiberglass was still very permeable. A similar observation was made during the 4-row test. In this test no water ran out of the holes which were above the water level in the half-full drain.

A third possibility is that fine particles from the soil collected at the soilfilter interface, partially sealing it. This is doubtful, however, since this phenomenon would be expected to occur over a period of time while flow was taking place, not while the drain was closed.

TABle 4

SUMMARY OF FLOW DATA FROM EXPERIMENTAL TANK

\begin{tabular}{|c|c|c|c|c|c|c|}
\hline \multirow{2}{*}{ Rows open } & \multirow{2}{*}{$\begin{array}{l}\text { Quantity } \\
\text { symbol }\end{array}$} & \multicolumn{5}{|c|}{$\begin{array}{l}\text { Flow* from filtered and nonfiltered drains } \\
\text { Cubic feet per foot per day with perforation } † \text { spacing of : }\end{array}$} \\
\hline & & 1.5 inches & 3.0 inches & 6.0 inches & 12.0 inches & 36.0 inches \\
\hline $\mathbf{A}$ & 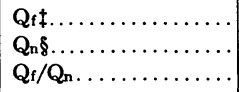 & $\begin{array}{l}0.0355 \\
0.0150 \\
2.367\end{array}$ & $\begin{array}{l}0.0350 \\
0.0040 \\
8.750\end{array}$ & $\begin{array}{l}0.0355 \\
0.0020 \\
17.750\end{array}$ & $\begin{array}{l}0.0355 \\
\cdots \cdots \\
\cdots \cdots\end{array}$ & $\begin{array}{l}0.0350 \\
\cdots \cdots \\
\cdots \cdots\end{array}$ \\
\hline$A$ and $B$ & 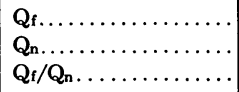 & $\begin{array}{l}0.0330 \\
0.0420 \\
0.786\end{array}$ & $\begin{array}{l}0.0340 \\
0.0370 \\
0.919\end{array}$ & $\begin{array}{l}0.0400 \\
0.0315 \\
1.270\end{array}$ & $\begin{array}{l}0.0350 \\
\cdots \cdots \\
\cdots \cdots\end{array}$ & $\begin{array}{l}\cdots \cdots \\
\cdots \cdots \\
\cdots \cdots\end{array}$ \\
\hline$A, B, C$, and D & 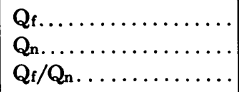 & $\begin{array}{l}0.0595 \\
0.0465 \\
1.280\end{array}$ & $\begin{array}{l}0.0590 \\
0.0415 \\
1.422\end{array}$ & $\begin{array}{l}0.0555 \\
0.0425 \\
1.306\end{array}$ & $\begin{array}{l}\cdots \cdots \\
\cdots \cdots \\
\cdots \cdots\end{array}$ & $\begin{array}{l}\cdots \cdots \\
\cdots \cdots \\
\cdots \cdots\end{array}$ \\
\hline
\end{tabular}

* Flows as listed were measured from a half-drain.

$\dagger$ Perforation diameter $=\frac{1}{4}$ inch; depth, 3 feet; spacing, 16 feet; depth of ponded water, 6 inches.

$Q_{f}=$ Flow from filtered drain.
$\& Q_{n}=$ Flow from nonfiltered drain. 


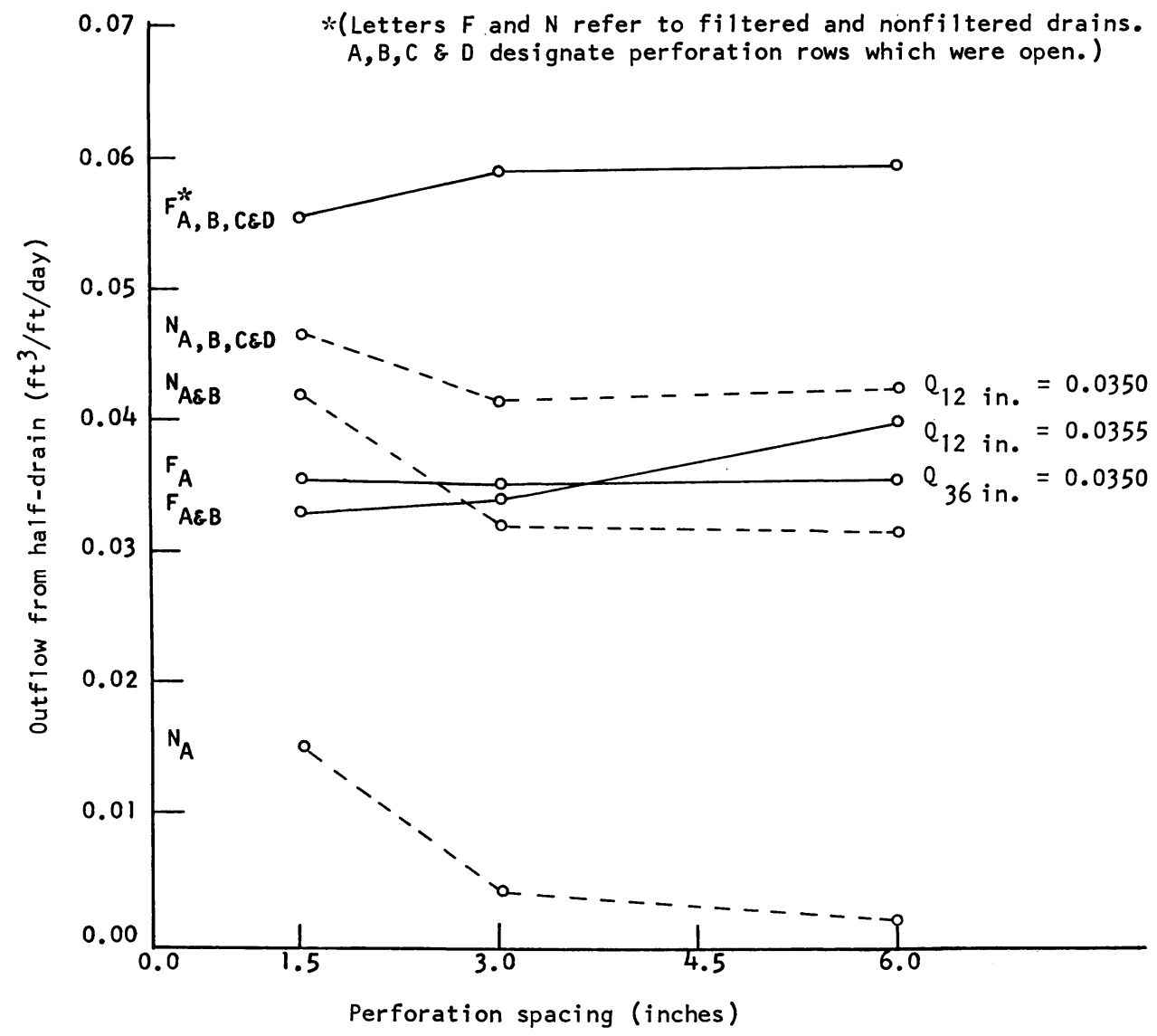

Fig. 5. Relationship between outflow and perforation spacing.

It appears, then, that some factor which changed with time-rather than the number of open rows of perforations-was responsible for the change in outflow from the filtered drain. Additional work is necessary to evaluate fully the effect of the number of rows of perforations. Concerning the longitudinal spacing of perforations in the filtered drain, the data show that this had little effect on outflow. For example, with row A open there was no difference in the flow measured at 1.5- and 36-inch perforation spacings. During these tests the soil in the tank was essentially puddled. As a result, the hydraulic conductivity was very low $(0.018 \mathrm{ft} /$ day $)$. If the conductivity had been greater, the flow rate would have been higher and some limiting value of perforation spacing might have been indicated.

Since most of the observed ratios of $\frac{Q_{\text {filtered }}}{Q_{\text {nonfiltered }}}$ were less than those predicted by Kirkham (1950) in comparing flow to drain tile and porous tubes, the theoretical outflow as a function of perforation spacing was calculated and compared with measured outflow. Such comparison would afford an examination of the data to evaluate whether nonuniform packing of the soil or other factors could have influenced the results of the study. The theoretical outflow was calculated from an equation proposed by Kirkham and Schwab (1951), after slightly modifying the equation to fit the geometry of the experimental 


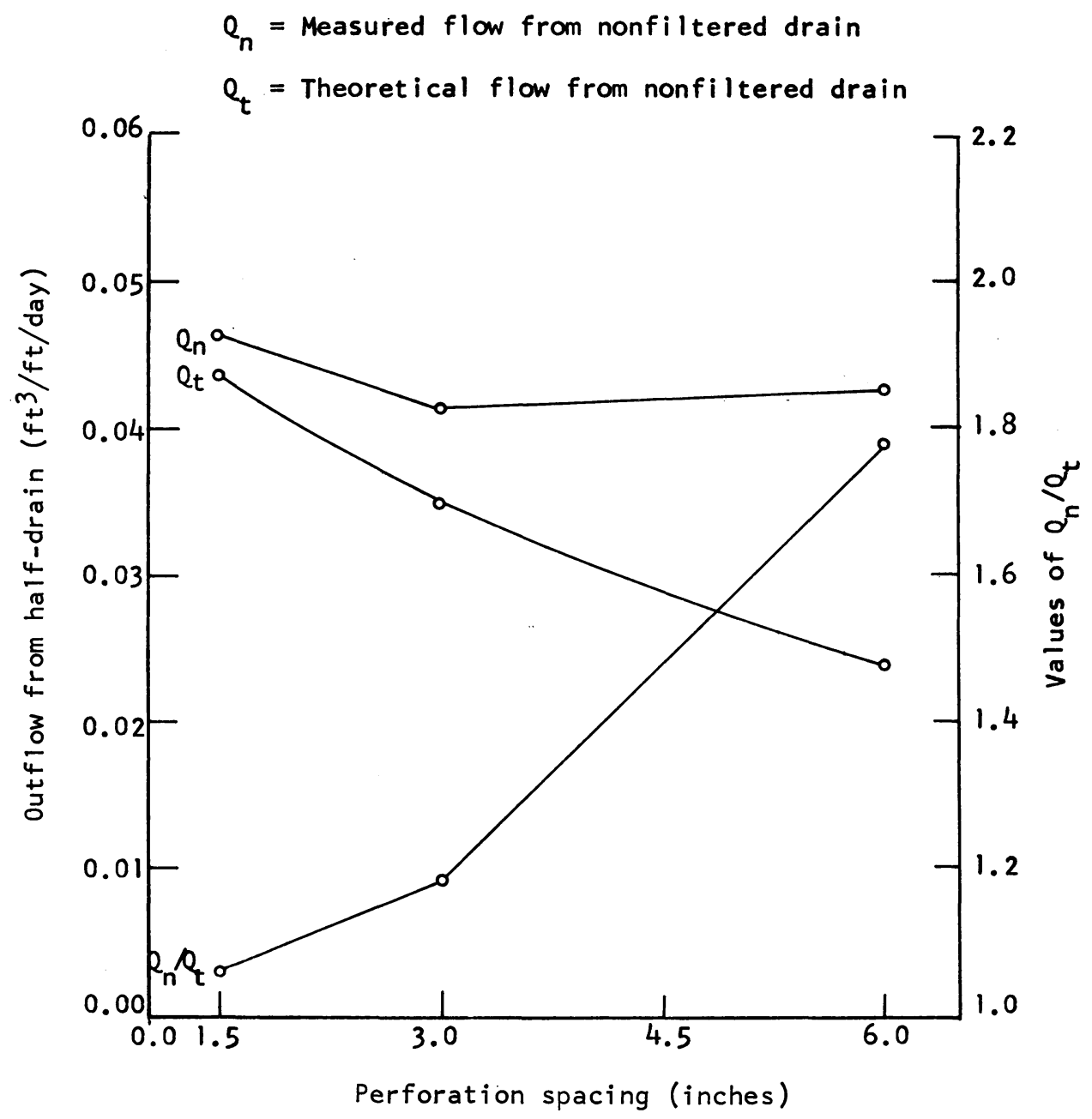

Fig. 6. Relationship between theoretical and measured outflow, and perforation spacing in nonfiltered drain.

drain installation and after adding a correction listed by Kirkham (1954). Calculations were made only for the condition of all four rows of perforations open, since this is the only situation which satisfied the boundary conditions of the equation.

Figure 6 shows the relationships between both theoretical and measured outflow and perforation spacing in the nonfiltered drain. (Also see table 5.) For the 1.5-inch perforation spacing there was very little difference between theoretical and measured out- flow, whereas for the 6-inch spacing the ratio of measured to theoretical was 1.78. These data give credence to the hypothesis that lateral flow took place along the soil-drain pipe interface of the nonfiltered drain, increasing the rate of flow above what was expected. After the tank experiments were complete, the soil around the drain was probed with a stiff wire. Indications were that the soil was more densely packed around the top of the drain than around the side or bottom. If this was the case, it would explain why the ratio 
TABLE 5

SUMMARY OF THEORETICAL AND EXPERIMENTAL NONFILTERED DRAIN OUTFLOW DATA

\begin{tabular}{|c|c|c|c|}
\hline 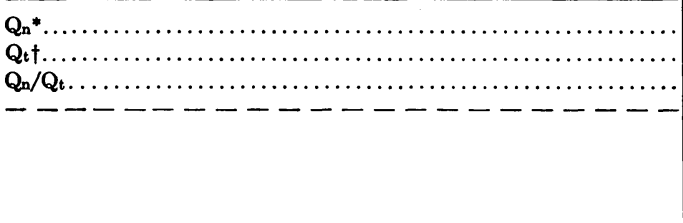 & $\begin{array}{r}0.0465 \\
0.0438 \\
1.062 \\
----- \\
\text { "C" } \\
0.7166\end{array}$ & $\begin{array}{c}\begin{array}{c}0.0415 \\
0.0350 \\
1.186 \\
----\end{array} \\
\text { for theoretic } \\
1.4341\end{array}$ & $\begin{array}{l}0.0425 \\
0.0239 \\
1.778 \\
----- \\
\text { ation } \ddagger \\
3.0920\end{array}$ \\
\hline
\end{tabular}

* $Q_{n}$ denotes measured flow from nonfiltered drain.

$+Q_{t}$ denotes theoretical flow from nonfiltered drain. $\ddagger$ See Kirkham and Schwab, 1951.

of $\frac{Q_{\mathrm{filtered}}}{Q_{\text {nonfiltered }}}$ was so much greater when the uppermost, or A, row of perforations was opened than when $\mathrm{A}$ and $\mathrm{B}$ rows or $\mathrm{A}, \mathrm{B}, \mathrm{C}$, and $\mathrm{D}$ rows were opened. The interface problem apparently developed only along the side and lower part of the drain. It therefore seems reasonable to assume that, if the soil had been packed more uniformly around the nonfiltered drain, the flow to it would have been less than recorded for the wider perforation spacings.

\section{SUMMARY AND CONCLUSIONS}

A series of tests was made to evaluate the use of thick fiberglass materials as a substitute for gravel filters around subsurface drains and to study the effect of perforation spacing on inflow to filtered drain pipe. Included in the tests were measurements of the thickness of several materials when placed under compressive loads in the range of 2 to 10 psi. This is within the range of pressures that might be expected under field conditions. Also, the hydraulic conductivity in a longitudinal direction through these materials was determined for various states of compressive loading. The purpose of the latter test was to indicate whether or not water could move freely to an opening in a drain pipe once it entered the filter material.

For the perforation spacing studies, both filtered and nonfiltered drains were installed in a large steel tank. Under ponded conditions the flow from these drains was measured for several arrangements of perforations in the drains. For the nonfiltered drain, theoretical and measured flows were compared to obtain an indication of the uniformity of soil packing around the drain.

From the results of the experiments and studies of background information, the following is concluded:

1. Within the range of loading ordinarily expected under field conditions, the thickness of the fiberglass filter materials tested is greatly reduced from that measured in the uncompressed state. This change in thickness depends on (a) initial thickness, (b) initial density, and (c) to some extent, manufacturing processes.

2. The hydraulic conductivity of the fiberglass materials was high and essentially varied little with load or samples of different thicknesses and densities. All " $\mathrm{K}$ " values measured 
were within the range given by other workers for clean sands or mixtures of clean sands and gravels.

3. For ponded water conditions, inflow to a filtered drain is greater than that to a nonfiltered drain with a similar perforation arrange- ment. Inflow to the filtered drain was affected very little by perforation spacing, whereas inflow to the nonfiltered drain varied considerably. Experimental results were influenced by a time effect not related to perforation spacing. 


\section{LITERATURE CITED}

\section{KIRKHAM, DON}

1950. Potential flow into circumferential openings in drain tubes. J. Appl. Phys. 21(7):655660.

1954. Seepage of artesian and surface water into drain tubes in stratified soil. Trans. Am. Geophys. Union 35(5):775-790.

Kirkham, DoN, and G. O. SchWAB

1951. The effect of circular perforations on flow into subsurface drain tubes. Part I. Theory. Agric. Eng. 32(4):211-214.

Nelson, R. William

1960. Fiberglass as a filter for closed tile drains. Agric. Eng. 41(10):690-693, 700 .

Roe, Harry B., and Q. C. Ayres

1954. Engineering for agricultural drainage. McGraw-Hill Book Company, New York. 501 p. SCHWAB, G. O., and DON KIRKHAM

1951. The effect of circular perforations on flow into subsurface drain tubes. Part II. Experiments and results. Agric. Eng. 32(5):270-274.

ToDD, DAvid K.

1960. Ground water hydrology. John Wiley and Sons, New York. 336 p. 
The journal HILGARDIA is published at irregular intervals, in volumes of about 650 to 700 pages. The number of issues per volume varies.

Single copies of any issue may be obtained free, as long as the supply lasts; please request by volume and issue number from:

\section{Agricultural Publications \\ University Hall \\ University of California \\ Berkeley 4, California}

The limit to nonresidents of California is 10 separate titles. The limit to California residents is $\mathbf{2 0}$ separate titles.

The journal will be sent regularly to libraries, schools, or institutions in one of the following ways:

1. In exchange for similar published material on research.

2. As a gift to qualified repository libraries only.

3. On a subscription basis $-\$ 7.50$ a year paid in advance. All subseriptions will be started with the first number issued during a calendar year. Subscribers starting during any given year will be sent back numbers to the first of that year and will be billed for the ensuing year the following January. Make checks or money orders payable to The Regents of The University of California; send payment with order to Agricultural Publications at above address. 